0,5\% колхаминовая мазь представляет собой густую массу желтоватого цвета с характерным запахом. Данную мазь назначают при эндо- и экзофитных раках кожи I и II стадии. [5]

Вывод: выявлено, что в настоящее время перечисленные в статье алкалоиды способны не только замедлять развитие опухолевых заболеваний, но и способны приводить к гибели опухолей.

$$
* * *
$$

1. Г. К Никонов, Б.М. Мануйлов. Основы современной фитотерапии. Учебное пособие для слушателей системы послевузовского образования для врачей. - М.: Медицина, 2005 - 520 с.

2. В.В. Маршак. Онкологические заболевания: профилактика и методы лечения. - М.: Новый издательский дом, 2004 - 352 с.

3. А.С. Васильев, Г.И. Калинкина, В.Н. Тихонов. Лекарственные средства растительного происхождения. Справочное пособие. / под редакцией профессора С.Е. Дмитрука. - Новосибирск: ОГУП "Центр фармацевтической информации", 2004 - 124 с

4. М.Д. Машковский. Лекарственные средства - 16 изд., перераб., испр., и доп. -М.: Новая волна: Издатель Умеренков,2020,- 1216с.

5. Государственная фармакопея XIV издания IV том, 2018

\title{
Цибизова А.А.
}

\section{Изучение мембраностабилизирующей активности экстракта Tamarix ramosissima}

Астраханский государственный медицинский университет (Россия, Астрахань)

doi: 10.18411/trnio-01-2022-215

\section{Аннотация}

Работа посвящена изучению мембраностабилизирующей активности экстрактов листьев Tamarix ramosissima на культуре Paramecium caudatum. Экстракты получены методом мацерации в соотношениях 1:1 и 1:2. Установлено, что наиболее выраженное мембраностабилизирующее действие оказывает экстракт листьев Tamarix ramosissima, полученного в соотношении $1: 2$, что актуализирует необходимость детального исследования экстрактов Тамарикса с целью получения на их основе новых лекарственных форм.

Ключевые слова: фитопрепараты, экстракт, Tamarix ramosissima, Paramecium caudatum, мембраностабилизирующая активность.

\section{Abstract}

The work is devoted to the study of membrane-stabilizing activity of Tamarix ramosissima leaf extracts on Paramecium caudatum culture. The extracts were obtained by maceration in ratios of $1: 1$ and 1:2. It was found that the most pronounced membrane stabilizing effect is provided by Tamarix ramosissima leaf extract obtained in a ratio of 1:2, which actualizes the need for a detailed study of Tamarix extracts in order to obtain new dosage forms based on them.

Keywords: phytopreparations, extract, Tamarix ramosissima, Paramecium caudatum, membrane stabilizing activity.

В задачи современной фармакологии и фармации входит разработка новых безопасных и эффективных лекарственных средств, оказывающих разностороннее действие на организм [3]. Перечисленным требованиям в полной мере отвечают фитопрепараты, использование которых возможно после проведения ряда исследований, включающих фитохимический анализ и исследование биологической активности лекарственного растения [4]. Особый интерес представляет из них является Тамарикс ветвистый (Tamarix ramosissima). Фитопрепараты, полученные на основе данного растения оказывают противовоспалительное, регенераторное, вяжущее, антиоксидантное, диуретическое и др. виды действия, которые обусловлены химическим состава растения $[5,6]$. Установлено, что 
листья Тамарикса содержат флавоноиды, дубильные вещества, сапонины, эфирные масла и др. биологически активные вещества, которые обеспечивают возможность успешного применения фитопрепаратов Тамарикса для лечения заболеваний пищеварительной и мочевыводящей систем, ревматизма, а также для лечения патологии кожных покровов [2].

Цель исследования - изучение мембраностабилизирующей активности экстрактов листьев Tamarix ramosissima.

Материалы и методы. Объектом исследования явился экстракты листьев Tamarix ramosissima, приготовленный в соотношении 1:1 и 1:2 методом мацерации с последующей отгонкой экстрагента (водно-спиртового раствора 60\%) с помощью ротационного испарителя.

Мембраностабилизирующее действие экстрактов листьев Tamarix ramosissima оценивали по характеру двигательной активности Paramecium caudatum. В качестве токсиканта использовали 10\%-ный раствор натрия хлорида [1].

В ходе исследования на предметное стекло наносили четыре пробы с Paramecium caudatum в объеме 0,05 мл. Далее к одной пробе добавляли 0,05 мл дистиллированной воды (контроль 1), другой этот же объем $10 \%$ раствора натрия хлорида (контроль 2), к двум оставшимся приготовленные экстракты листьев Tamarix ramosissima. После чего фиксировали время остановки парамеций в каждой пробе в трех повторностях.

Результаты и обсуждения. В таблице представлены результаты оценки мембраностабилизирующего действия экстрактов листьев Tamarix ramosissima.

Мембраностабилизирующее действие экстрактов листьев Tamarix ramosissima

\begin{tabular}{|c|c|c|}
\hline Исследуемая среда & $\begin{array}{c}\text { Характер движения } \\
\text { парамеций через 2 мин. }\end{array}$ & $\begin{array}{c}\text { Время } \\
\text { остановки } \\
\text { движения, мин }\end{array}$ \\
\hline Дистиллированная вода & Активные & $3,6 \pm 0,40$ \\
\hline $10 \%$ раствор натрия хлорида & Неактивные & $2,0 \pm 0,30^{* *}$ \\
\hline Экстракт 1:1 & Умеренно активнье & $2,7 \pm 0,21^{\#}$ \\
\hline Экстракт 1:2 & Активные & $3,0 \pm 0,26^{\#}$ \\
\hline
\end{tabular}

Примечание: ** - $\leq \leq 0,01$ в сравнении с контролем $1 ;^{\#}-\mathrm{p} \leq 0,05$ в сравнении с контролем 2 .

При оценке мембраностабилизирующего действия экстрактов листьев Tamarix ramosissima было установлено, что в $10 \%$ растворе натрия хлорида парамеции становились неактивными к концу 2 минуты наблюдений; в среде экстракта, полученного в соотношении 1:1 - движения через минуты были характер умеренно-активные, в соотношении 1:2 активные и сравнимые с дистиллированной водой.

Время остановки парамециев в $10 \%$ растворе натрия хлорида уменьшилось на $44 \%$ $(\mathrm{p} \leq 0,01)$ в сравнении с контролем 1. В экстракте листьев Tamarix ramosissima приготовленного в соотношении $1: 1$ данный показатель был на $25 \%(\mathrm{p} \geq 0,05)$ меньше, чем в контроле 1 и больше контроля 2 на $35 \%(\mathrm{p} \leq 0,05)$. В экстракте плодов $1: 2$ - время остановки движения уменьшилось в сравнении с контролем 1 и увеличилось по отношению ко второму контролю на $17 \%(\mathrm{p} \geq 0,05)$ и $50 \%(\mathrm{p} \leq 0,05)$ соответственно.

Таким образом, полученные результаты свидетельствуют о выраженном мембраностабилизирующем действии экстракта листьев Tamarix ramosissima, полученного в соотношении 1:2, что актуализирует необходимость детального исследования экстрактов Tamarix ramosissima с целью получения на их основе новых лекарственных форм.

$$
* * *
$$

1. Василиади О. И., Кузьминова Е. В., Семененко М. П., Власенко А. А. Изучение мембраностабилизирующей активности фитопрепаратов с использованием тест-системы Paramecium caudatu //Международный научноисследовательский журнал. 2021. №. 4-1 (106). С. 152-155.

2. Великородов А. В., Пилипенко В. Н., Пилипенко Т. А., Тырков А. Г. Изучение химического состава эфирного масла Tamarix Ramosissima // Химия растительного сырья. 2017. №. 4. 
3. Селимзянова Л. Р., Вишнёва Е. А., Федосеенко М. В., Промыслова Е. А. Фитотерапия: современное состояние вопроса // Педиатрическая фармакология. 2016. Т. 13. №. 5.

4. Токтоналиев И. У. Место и роль фитопрепаратов в современной медицинской практике // Наука, новые технологии и инновации Кыргызстана. 2017. №. 7. С. 108-111.

5. У Уарова Г.Н., Цибизова А.А., Ахадова А.А., Киселева А.А., Сальникова Д.А. Регенераторная активность экстракта Tamarix ramosissima // В сборнике: Гуманитарные. естественно-научные и технические аспекты современности. Материалы XXXIII Всероссийской научно-практической конференции. В 2-х частях. Ростов-на-Дону. 2021. С. 134-138.

6. Ц Цибизова А.А., Каштанова О.А. Оценка местно-раздражающего действия экстракта Tamarix ramosissima $1 / /$ В сборнике: Научная реальность и образы будущего в контексте междисциплинарных исследований. Материалы XXXVIII Всероссийской научно-практической конференции. Ростов-на-Дону. 2021. С. 360-362. 